\title{
An Assessment Approach to Project-Based Service Learning
}

\section{Ms. Antonette T. Cummings, Purdue University}

Antonette Cummings is a Ph.D. student in Engineering Education at Purdue University. She holds an M.S. in Mechanical Engineering from the University of Texas at Austin.

\section{James Huff, Purdue University}

James L. Huff is a Ph.D. candidate in Engineering Education at Purdue University as well as the assistant education administrator for EPICS. He earned his B.S. in Computer Engineering at Harding University and an M.S. in Electrical and Computer Engineering at Purdue University. He is currently on an academic leave from his role as an instructor of engineering at Harding University. His research interests include professional socialization of engineers, social cognition in engineering, community-driven design, and interpretive phenomenology.

\section{Dr. William C. Oakes, Purdue University, West Lafayette}

Dr. William "Bill" Oakes is the director of the EPICS program and one of the founding faculty members of the School of Engineering Education at Purdue University. He has held courtesy appointments in Mechanical, Environmental and Ecological Engineering as well as Curriculum and Instruction in the College of Education. He is a registered professional engineer and on the NSPE board for Professional Engineers in Higher Education. He has been active in ASEE serving in the FYP, CIP and ERM. He is the past chair of the IN/IL section. He is a fellow of the Teaching Academy and listed in the Book of Great Teachers at Purdue University. He was the first engineering faculty member to receive the National Campus Compact Thomas Ehrlich Faculty Award for Service-Learning. He was a co-recipient of the National Academy of Engineering's Bernard Gordon Prize for Innovation in Engineering and Technology Education and the recipient of the National Society of Professional Engineers' Educational Excellence Award and the ASEE Chester Carlson Award. He is a fellow of the American Society for Engineering Education and the National Society of Professional Engineers.

\section{Dr. Carla B. Zoltowski, Purdue University, West Lafayette}

Dr. Carla B. Zoltowski, Ph.D., is education administrator of the EPICS Program at Purdue University. She received her B.S. and M.S. in Electrical Jngineering and Ph.D. in Engineering Education all from Purdue University. She has served as a lecturer in Purdue's School of Electrical and Computer Engineering. Dr. Zoltowski's academic and research interests include human-centered design learning and assessment, service-learning, ethical reasoning assessment, leadership, and assistive technology. 


\title{
An Assessment Approach to Project-Based Service Learning
}

\begin{abstract}
Strategies for assessment are important to engineering educators and researchers as they evaluate the quality of student learning in courses and other experiences. Assessment can be particularly challenging in project-based service-learning (PBSL) experiences because the types of learning do not lend themselves to traditional modes of assessment, such as tests or quizzes. This paper describes a strategy of assessing a broad set of skills in EPICS, a well-established and recognized PBSL program where students earn academic credit for their work on community-based designs. Although the assessments presented are specific to a particular program, we present them here with sufficient detail and underlying objectives so that they can be adapted to other courses and programs as appropriate. Assessments discussed include individual learning, team and project assessments and programmatic assessments including alumni surveys.
\end{abstract}

\section{Introduction}

Project-based service-learning experiences in engineering have been developed and deployed in multiple settings to meet education needs of students as well as human, environmental and societal needs. Student learning includes applying technical knowledge to the community-based problems as well as the development of the broader set of skills that are included in ABET's Engineering Criteria 2000 outcomes.

Research continues on developing good assessment tools for all of the ABET outcomes, including the use of open and close-ended surveys administered to alumni of engineering programs for multiple layers of assessment. The technical outcomes include (a) an ability to apply knowledge of mathematics, science, and engineering (b) an ability to design and conduct experiments, as well as to analyze and interpret data (c) an ability to design a system, component, or process to meet desired needs within realistic constraints such as economic, environmental, social, political, ethical, health and safety, manufacturability, and sustainability (e) an ability to identify, formulate, and solve engineering problems (k) an ability to use the techniques, skills, and modern engineering tools necessary for engineering practice. The professional outcomes include (d) an ability to function on multidisciplinary teams (f) an understanding of professional and ethical responsibility $(\mathrm{g})$ an ability to communicate effectively (h) the broad education necessary to understand the impact of engineering solutions in a global, economic, environmental, and societal context (i) a recognition of the need for, and an ability to engage in life-long learning ( $\mathrm{j}$ ) a knowledge of contemporary issues.

In traditional coursework, assignments can be designed to elicit artifacts that can demonstrate mastery of desired outcomes. Project-based service-learning experiences, however, often do not follow prescribed timelines and the scaffolding around the experiences has to allow for the 
evolution of the experience as the projects develop out of the interaction with the students, community and faculty. This fluidity adds to the assessment challenges. Furthermore, many of the desired student outcomes may not manifest themselves until well after the students have graduated.

The Engineering Projects in Community Service (EPICS) program at Purdue University has addressed these challenges in our assessment approaches. EPICS began at Purdue in 1995 and has grown to include over fifty universities and high schools ${ }^{[1]}$ EPICS is an engineeringcentered, multidisciplinary, service-learning program that supports a series of integrated elective courses that partner with the community locally and abroad ${ }^{[2]}$. EPICS shares many common traits with other service-learning models ${ }^{[3]}$. EPICS is explicitly multidisciplinary with over 70 majors participating in a typical year and draws students from their first-year to senior year. The curricular structure is designed to allow students to participate over multiple semesters or even years. The long-term student participation allows projects to be developed over multiple semesters or years and allows EPICS to address more complex and compelling needs than could be addressed in a single semester. The approach also supports and develops reciprocal partnerships with the community.

An EPICS team is defined by its relationship with a community partner rather than being defined by a specific project. Consequently, a single EPICS division typically supports multiple projects concurrently, with students working on individual projects on smaller sub-teams. The teams identify the needs in conversations with the community partner and will often continue the project across multiple semesters. Once projects are deployed to the community partner, new projects are identified with the same partner. The relationships that define the individual teams are intentionally long-term. This structure provides students with an authentic experience and many opportunities to demonstrate competencies expected of them. In 2013, EPICS supports over 90 projects distributed across over 31 teams.

The program is structured with student-led divisions, each with 8-20 students, a faculty or industry mentor, and a graduate teaching assistant (TA). Each division has one or more not-forprofit agency/ies (such as a museum, government service, charity, etc.) as a community partner(s). The students work with their community partner(s) to identify, develop, and deliver projects that meet the community partner's needs. Examples of such community needs include designing assistive technology for people with disabilities, developing database software for human services agencies, and developing engaging science-educational technology for elementary students. Additional projects can be seen at https://engineering.purdue.edu/EPICS/Projects/Teams.

\section{Assessment Philosophy}

The overall assessment philosophy of EPICS is guided by two core values of EPICS. First, EPICS seeks to provide an educational experience that will prepare students for professional 
practice. Second, we seek to meet compelling human, environmental and community needs. The assessment processes are integrated into the curriculum and designed to create artifacts that can be assessed. A key concept in PBSL assessment is to utilize authentic project artifacts (papers, reports, notebooks, blogs, reflections, etc.) that can be assessed and used to demonstrate student learning. Whenever possible, the assessments are integrated into processes and activities that advance learning, prepare students for their profession and add value to the community.

These principles are employed along four dimensions of the program: 1) individual student learning and grading, 2) team and project assessment, 3) community impact and 4) program assessment. Examples of each of the dimensions are discussed below.

\section{Individual Assessment}

A significant challenge for EPICS to assess individuals is the variability in students who come from first-year to senior and from about 70 majors with different expertise and experiences to bring to the project. In addition, EPICS decouples the project timelines from the academic calendar so students may start the semester with a new project or they can be picking up a project that was not completed in the previous semester. The assessment process for individual students is designed to customize the assessment process to each student. This process is modeled after the performance appraisal systems used in the corporate world. The first step in the assessment process is for students to establish their goals and expectations for the semester. They do this with the faculty member who oversees that section of EPICS. The parallel in industry is that an employee would set goals for the year or some period typically longer than the semester. Once the goals have been determined, progress toward the goals is documented and evaluated with the Individual Evaluation Rubric, shown in Appendix A. This allows students to identify their goals and point to artifacts that document activities and learning in five evaluation criteria:

1. Accomplishments

2. Process

3. Reflective/Critical Thinking

4. Teamwork/Leadership

5. Communication

EPICS emphasizes the production of authentic individual and team artifacts that can be assessed. These include notebooks, blogs, electronic portfolios, reports and design documents. These artifacts are recommended to contain any sketches, ideas, summaries, and reflections of learning. We do not prescribe that such records be kept in a specific format and/or medium. Rather, we allow students to use the media they are most comfortable with, and the content is the focus of the assessment. The Individual Evaluation Rubric is used for students to point us to the artifacts so that they can be graded. The reflections are guided with questions from the instructors as part of the weekly activities in EPICS at Purdue. Open-ended written reflection is another way of 
gauging learning. Researchers have used these data from students to assess their learning of ethics, design, and teamwork ${ }^{[4]}$.

The Individual Evaluation Rubric allows students to conduct a self-assessment which allows them to receive feedback on their work, thinking and learning as well as their ability to selfevaluate. Rubrics are provided that describe what is needed for each grade and they are included in Appendix B. The multidisciplinarity of EPICS can create challenges but we have developed assessment tools that can be used for all majors. The assessment are based on the ABET language but with "engineering" replaced by "your discipline" and "technical" with "disciplinary". This allows each student to read into his or her expertise and be evaluated against the criteria. Using terms like "professional preparation" allows the tools to be used across majors effectively. In addition, Peer Evaluation and Feedback are also done for each student in each team. They include self-evaluation and anonymous evaluations from peers that are used to supplement the individual documentation.

\section{Project Evaluations}

Project Evaluations are done for each team. The individual grade is a combination of their team and individual work. The projects are evaluate with another rubric, shown in Appendix $\mathrm{C}$ as the Project Evaluation Rubric. Modeled after the individual rubric, this is designed for the teams to self-evaluate their work and for the instructors to give feedback on the work. Again, they have the opportunity to point to artifacts that show their progress. Other team assessments are made on projects include prototypes, demos, and completed projects which are evaluated by the instructor as well as design reviewers from industry and the community. Community Partners also evaluate the teams and provide feedback on their communication, quality of work and the quality of the projects.

\section{Community Impact}

Community impact is not a traditional assessment criterion in engineering but it is the community engagement and service-learning arena. EPICS has maintained partnerships for many years. Two of the original partners from 1995 are still active. The main way this is done is through relationship building. Staff and faculty from the program are in regular contact with the partners. We intentionally have staff who are not part of the grading process talk with the partners periodically to see if there are any challenges. Instructors seek the input from the partners each semester as part of the grading process on the work and communication with the teams. This creates a multi-layered approach to the community partner relationships. When a project is delivered, a survey is included in the delivery process to provide another manner of assessment. This survey is included in Appendix D. 
Programmatic Assessment

Programmatic assessment follows the ABET philosophy of gathering information to inform the development of the program. Summative course evaluations are done each semester. These anonymous evaluations are not part of the grading process. Course evaluations are done on the course, teaching assistants and instructors and include self-reflections on their own learning. An example of the self-reflection is a question where students were asked to identify the three most important things they learned from the PBSL program. Results are shown in Table 1 below.

Table 1. Student responses to the question: What are the three most valuable things you have learned from being a part of EPICS? ${ }^{[5]}$

\begin{tabular}{|l|c|}
\hline $\begin{array}{l}\text { Categories of responses (with representative variations of } \\
\text { comments) }\end{array}$ & $\begin{array}{c}\text { Number of student } \\
\text { responses }\end{array}$ \\
\hline $\begin{array}{l}\text { Teamwork (teamwork, working with others, cooperation, } \\
\text { accountability) }\end{array}$ & 534 \\
\hline $\begin{array}{l}\text { Leadership (Leadership, responsibility, motivating self and others, } \\
\text { taking initiative) }\end{array}$ & 1008 \\
\hline $\begin{array}{l}\text { Communication (Communication skills, presentation skills, public } \\
\text { speaking, report writing, communicating with clients) }\end{array}$ & 793 \\
\hline $\begin{array}{l}\text { Organization and planning (organization, project planning, time } \\
\text { management, meeting deadlines and timelines, goal setting, }\end{array}$ & 754 \\
\hline $\begin{array}{l}\text { Technical skills (technical expertise, programming, design process, } \\
\text { testing, technical procedures) }\end{array}$ & 222 \\
\hline $\begin{array}{l}\text { Real World Experience (real applications, realistic view of working } \\
\text { world, experience for real life) }\end{array}$ & 174 \\
\hline Customer Awareness (Customer needs, customer support) & 155 \\
\hline $\begin{array}{l}\text { Community Awareness (Community needs, contribution to the } \\
\text { community, value of service) }\end{array}$ & 2044 \\
\hline \begin{tabular}{l} 
Total Number of respondents \\
\hline
\end{tabular} & \\
\hline
\end{tabular}

Alumni surveys are the newest form of programmatic assessment and were designed to provide a perspective from alumni after they have been out in the workforce. The survey items were designed to assess alumni with regard to the influence of EPICS on: (1) their careers, (2) their community involvement, and (3) their ability to connect their career/discipline to community engagement. The survey was also leveraged data for educational research that will be the subject of future papers. The survey questions are included in Appendix E. 


\section{Alumni Survey Development}

Multiple types of questions were designed to gather data related to the overarching goals. Seventeen (17) items gathered data regarding the extent to which EPICS contributed toward certain professional and/or personal learning. Three questions requested survey participants to rank undergraduate experiences vis-à-vis their salience in certain aspects of professional development (e.g., Q24). Further, we asked whether or not their participation in EPICS influenced their career choice, followed by an open-ended question asking how it affected this choice (Q36). Finally, we asked an open-ended question as to how EPICS benefited them professionally or personally (Q61). In addition we gathered demographic information, year of graduation, and major along with the nature of their experience in EPICS (e.g. Q4) and their undergraduate experiences (e.g., Q5). We also gathered information about the nature of employment initially sought and obtained upon graduation, as well as current employment (e.g., Q7, Q8, and Q15). We further asked questions regarding the nature of their work experiences (e.g., Q17 and Q39) and their community/civic engagement (e.g., Q51 and Q52). Some questions (e.g., Q6 and Q9) were placed in the questionnaire in order to ensure that only alumni with industry experience answered questions that necessitated such experience.

In order to mitigate question error ${ }^{[6]}$, the authors' research group provided feedback and then the survey was piloted with graduate students in Engineering Education. After the questions were finalized, the survey was administered through the on-line survey tool Qualtrics.

We were methodical in our approach for administering the survey, having recognized that this the elements process substantially affect the response rate to the survey ${ }^{[6]}{ }^{[7]}{ }^{[8]}{ }^{[9]}$. We received IRB approval for the research in late fall of 2011 and elected to administer the survey in the middle of January 2012, when we could reasonably posit that alumni had returned from holiday travel. Consistent with Dillman's recommendation, we opened the survey for a specific and limited time period of two weeks in order to encourage response.

We obtained the list of EPICS alumni' addresses and email addresses from our university's alumni office. As previously reported by Huff, Oakes, \& Zoltowski ${ }^{[10]}, 1556$ valid alumni email addresses were registered on this list. We contacted these participants by email throughout the survey's time period. Additionally, we sent postcards containing the web address of the survey to 1034 alumni that did not have a registered email address. This provided us a target population of 2590. Of these, 600 responded to the survey. Four of these participants declined to take the survey; 71 did not complete the survey; and one participant revealed himself as not actually have taken the course. When these were excluded from analysis, our final sample population was 523 participants.

Incentives increase the possibility of attracting respondents with a variety of experiences. As an incentive to complete the survey, we conducted a random drawing for two iPads. One iPad 
winner was randomly selected a week into the survey administration and the other winner was selected at the close of the survey. These drawings provided multiple opportunities to correspond with the alumni in order to update them on the status of the iPads. Such correspondences also helped increase our response rate. Of the fourteen-day period in which the survey was administered, approximately $75 \%$ of the responses were completed on the five days in which we delivered correspondences about the survey and/or iPad drawing.

Additionally, in order to be eligible for the iPad drawing, participants were asked to provide an email address. Then, they were asked if they were willing to be contacted for an interview. The purpose of the interview is to explore what aspects of EPICS contributed to their perspective on this class. As reported in Huff, Oakes, \& Zoltowski ${ }^{[10]}$, over $70 \%$ of participants agreed to be contacted. We examined the open-ended items (Q54 and Q61) in order to purposively sample 27 participants for these interviews. The sampling represents a diverse population in major, in number of semesters in EPICS, in gender, in type of experience in EPICS, and in era of the program. We further detail on these sampling procedures in a separate paper ${ }^{[11]}$.

\section{Lessons Learned}

An assessment program can be designed to be flexible enough to capture the diverse learning that occurs in project-based service-learning. Industry models of performance appraisals work well and provide another way to link PBSL to professional practice. Students can be made to be partners in the process and that can add to the learning experience. Artifacts need to be generated for assessment and these can add to the learning and project components. Reflections provide deeper learning and they offer an artifact that can be assessed. Documentation of the projects is critical to the longevity of the projects and needed by the partners and also creates artifacts. While not without challenges, the approach has worked well in EPICS for over 400 students per semester. The approaches have seen two rounds of ABET reviews and the comments have been very positive. The evaluation rubrics create a map to the student work and artifacts (a.k.a. portfolio) and these are evidence of the learning in the program.

The alumni survey yielded valuable information but as a first-time implementation, we learned lessons to improve. Through follow-on interviews, we discovered, a few interview participants inverted the rankings of questions that asked them to rank their undergraduate experiences $(\mathrm{Q} 24$, 35, and 50). We are not certain why this error occurred, but perhaps the items' instructions were too wordy to hold all of the survey participants' attention. Additionally, some interview participants interpreted the term "peers" differently than we intended when we asked them to compare their preparation and advancement to their "peers" (Q13 and Q23). While we intended them to compare their preparation and advancement to their co-workers (a more appropriate term), they often compared themselves to their friends outside of work or their former classmates. 
Furthermore, after conducting analysis on the survey data, we recognized how including some additional items could have helped us better interpret the results. For example, we did not ask whether or not a participant identifies themselves as an engineer. As we learned through subsequent interviews, one graduating with an engineering discipline does not necessarily suggest that $\mathrm{s} / \mathrm{he}$ is an engineer. Also, we do not ask about their classifications when they enrolled in EPICS, nor do we ask about their roles on design teams. Such data would certainly allow us to make meaningful comparisons within our survey participants. Finally, we do not ask about their nation of citizenship, which would have been helpful related to a respondent's civic engagement (Q37, Q38, and Q55) as these particular items are eliciting information from a U.S. perspective.

In spite of these issues, we found the questionnaire to be effective in eliciting relevant data for program assessment and educational research. We are able to compare data from these items to one another in order to infer how EPICS has influenced certain workplace skills and attitudes.

\section{Sample Results from the Alumni Study}

The results of the alumni survey are encouraging for the program and pointed to how such programs can prepare graduates for careers in industry. A full analysis of the data will be published in a future paper but examples are provided below that show the longer term impact of EPICS. For example, Q11 and Q12 (see Appendix) asked the respondents how well EPICS prepared them for applying design techniques and being prepared for the workplace. Figure 1 illustrates the high percentage of respondents who rated EPICS has at least "some extent" to be prepared to enter the workplace.

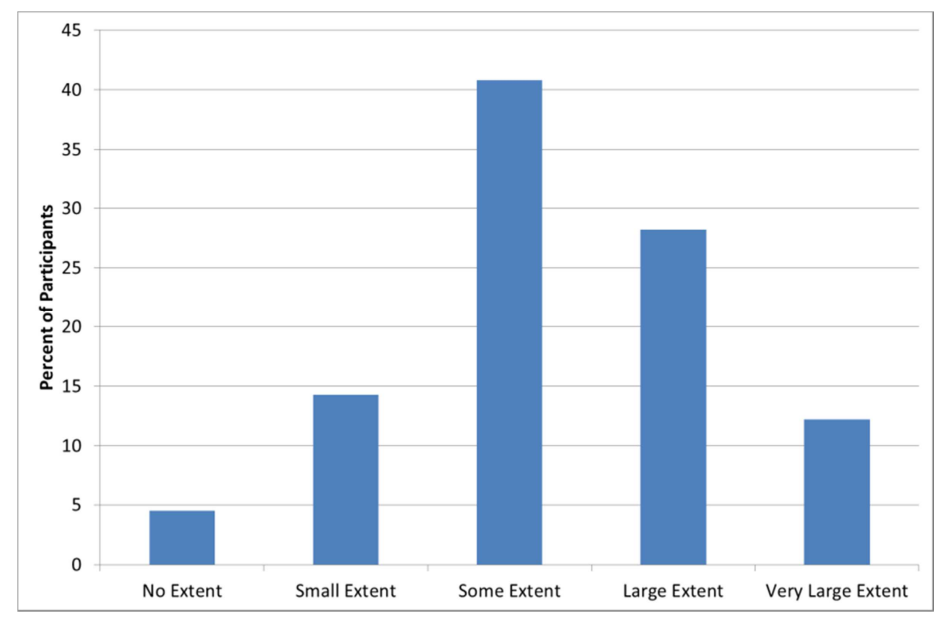

Figure 1. EPICS' contribution to participants' preparedness for the workplace. 
EPICS has at least "some extent" to a "very large extent" of impact to $80 \%$ of the respondents in recognizing engineering as benefitting society as shown in Figure 2 below.

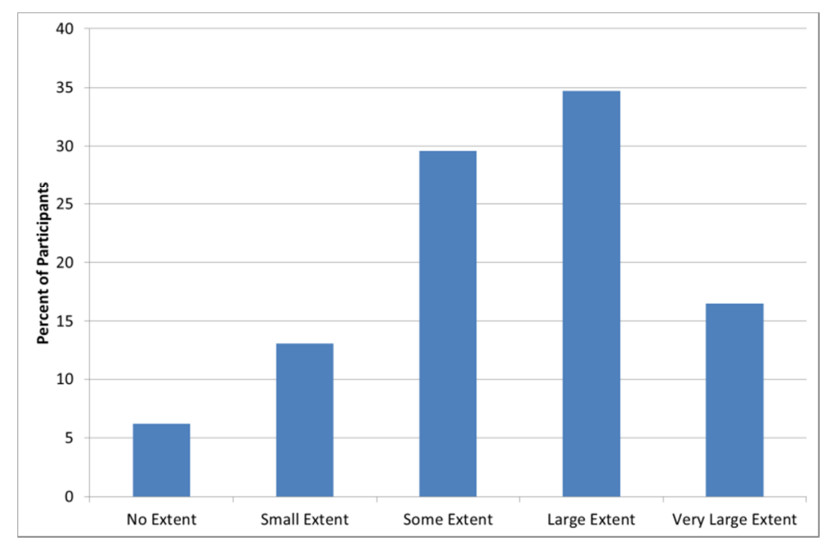

Figure 2. EPICS' contribution on participants' appreciation for engineering as benefitting society.

EPICS has at least "some extent" to a "very large extent" of impact for $61 \%$ of respondents' desire to be active in the local community, Figure 3. It was surprising that this was not higher but many of the students reported that they were already committed to being active and that is what drew them to the program.

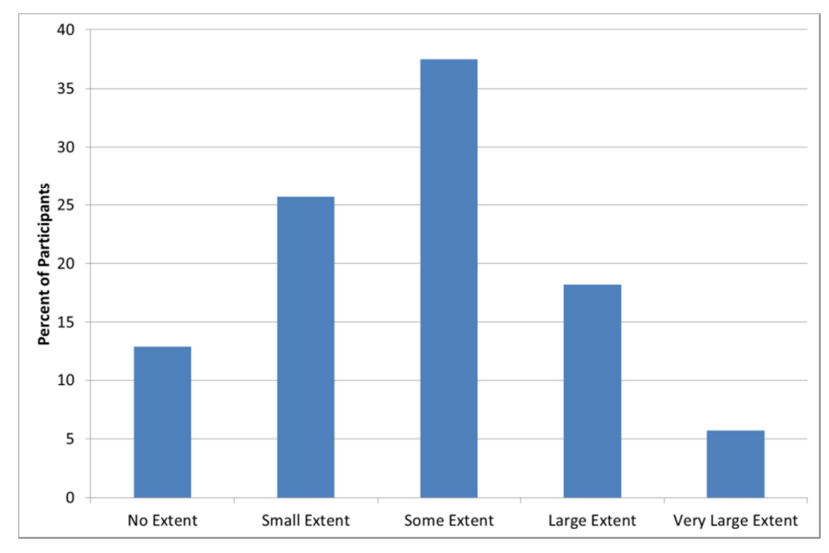

Figure 3. EPICS' contribution on participants' desire to play an active role in their local community.

\section{Conclusions}

Assessment is a key part of the academic process and in PBSL it takes on several facets. This paper shows how a multi-layered approach can be implemented to assess learning, programmatic outcomes and community impact. A survey of alumni can be used to support and inform a PBSL 
program. Assessment tools can be designed to be flexible to adapt to the fluidity of the PBSL environment. Corporate models for assessment of performance translate very well into PBSL and can add value to the program connecting it with industry in the eyes of the students.

Engaging students in their assessment is a significant benefit for PBSL and makes them part of the assessment team. Design tools that can be used across majors reduce the number of tools and documents and also create a culture where all students are on the same footing. Asking students to be evaluated related to their discipline allows individual majors to be assessed and has been looked at favorably by ABET during accreditation reviews.

The alumni data yielded sufficient numbers of responses to be significant. The results of the survey show that the PBSL experience is valuable in preparing students for the practice of engineering. The data also shows that students were impacted in their views toward the community and volunteering. While not a formal academic goal, these attributes are part of the program goals and the alumni survey provides a means to assess the impact of the program. The alumni data also adds to the data that we can use as a community to point to how communityengagement and PBSL is a valuable part of engineering education.

\section{Acknowledgments}

Thanks to the research group for guidance in developing the alumni survey: Monica Cardella, Patrice Buzzanell, Craig Titus, and Roy Melton.

\section{References}

[1] W. Oakes, E. Coyle and L. Jamieson, "EPICS: A Model of Service-Learning in an Engineering Curriculum," in Proceedings of the 2000 American Society for Engineering Education Annual Conference \& Exposition, 2000.

[2] E. Coyle, L. Jamieson and W. Oakes, "Integrating Engineering Education and Community Service: Themes for the Future of Engineering Education," Journal of Engineering Education, pp. 7-11, 2006.

[3] W. Oakes, "Creating Effective and Efficient Learning Experiences While Addressing The Needs Of The Poor: An Overview of Service-Learning in Engineering Education," in Proceedings of the 2009 American Society for Engineering Education Annual Conference \& Exposition, 2009.

[4] L. Slivovsky, F. DeRego, C. Zoltowski, L. Jamieson and W. Oakes, "An Analysis of the Reflection Component in the EPICS Model of Service Learning," in Proceedings of the 2004 American Society for Engineering Education Annual Conference \& Exposition, 2004.

[5] E. Coyle, L. Jamieson and W. Oakes, "EPICS: Engineering Projects in Community Service," International Journal of Engineering Education, pp. 1-12, 2005.

[6] D. Dillman, G. Phelps, R. Tortora, K. Swift, J. Kohrell, J. Berck and B. Messer, "Response rate and measurement differences in mixed-mode surveys using mail, telephone, interactive voice response (IVR) and 
the Internet," Social Science Research, pp. 1-18, 2009.

[7] M. Couper, M. Traugott and M. Lamias, "Web Survey Design and Administration," Public Opinion Quarterly, pp. 230-253, 2001.

[8] D. Frippiat, N. Marquis and E. Wiles-Portier, "Web Surveys in the Social Sciences: An Overview," Population, pp. 285-311, 2010.

[9] M. Millar and D. Dillman, "Improving Response to Web and Mixed-Mode Surveys," Public Opinion Quarterly, pp. 249-269, 2011.

[10] J. Huff, W. Oakes and C. Zoltowski, "Understanding Professional Competency Formation in a ServiceLearning Context from an Alumni Perspective," in Frontiers in Education, 2012.

[11] J. Immekus, S. Tracy, J. E. Yoo, S. Maller, B. French and W. Oakes, "Developing Self-Report Instruments to Measure ABET EC 2000 Criterion 3 Professional Outcomes," in Proceedings of the 2004 American Society for Engineering Education Annual Conference \& Exposition, 2004.

[12] A. Bielefeldt, K. Paterson and C. Swan, "Measuring the Impacts of Project-Based Service Learning," in Proceedings of the 2009 American Society for Engineering Education Annual Conference \& Exposition, 2009.

[13] A. Bielefeldt, K. Paterson and C. Swan, "Measuring the Value Added from Service Learning in Project-Based Engineering Education," International Journal of Engineering Education, pp. 535-546, 2010.

[14] R. Puerzer and D. Rooney, "The Alumni Survey as an Effective Assessment Tool for Small Engineering Programs," Journal of Engineering Education, pp. 109-116, 2002.

[15] E. Koehn and R. Malani, "Satisfying ABET Accreditation: Program Assessment," in Proceedings of the 2004 American Society for Engineering Education Annual Conference \& Exposition, 2004. 


\begin{abstract}
Appendix A - Individual Evaluation Rubric
Team: Student:

Course:

Roles: Week:

No. of semesters in EPICS:

Project(s):

Major:

In the following box, list all of your significant contributions and learning since the beginning of the semester and where documentation of those can be found (add lines as necessary). Mark an " $X$ " under the grading criteria you think are applicable for each item:
\end{abstract}

\begin{tabular}{|c|c|c|c|c|c|c|}
\hline $\begin{array}{l}\text { Contribution/Learning (e.g., completed user } \\
\text { analysis, data analysis, DFMEA, or prototype, } \\
\text { programmed microprocessor; learned CATIA) }\end{array}$ & $\begin{array}{l}\text { Where documentation can be found: } \\
\text { (include page \#s if in notebook and URLs } \\
\text { if online) }\end{array}$ & 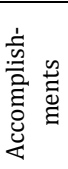 & 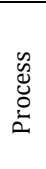 & 莺葛 & 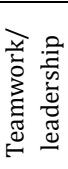 & 窇 \\
\hline & & & & & & \\
\hline & & & & & & \\
\hline & & & & & & \\
\hline & & & & & & \\
\hline
\end{tabular}

In the following box, list contributions and learning planned for rest of semester (N/A for final submission)

\begin{tabular}{|l|l|}
\hline Contribution/Learning: & To be completed by: ( ex: $9 / 20 / 11)$ \\
\hline & \\
\hline & \\
\hline & \\
\hline
\end{tabular}

Directions: Students mark an "X" and Advisors/TAs mark an "O" in the appropriate box for each criterion. Each of the criterion should be evaluated considering the student's course level, major, semester in EPICS, and number of credits.

\begin{tabular}{|c|c|c|c|c|c|c|c|c|c|c|c|c|c|}
\hline & \multicolumn{3}{|c|}{ Excellent } & \multicolumn{3}{|c|}{ Good } & \multicolumn{3}{|c|}{ Adequate } & \multicolumn{3}{|c|}{ Low passing } & \multirow[b]{2}{*}{$\mathrm{F}$} \\
\hline & $\mathrm{A}+$ & $\mathrm{A}$ & A- & $\mathrm{B}+$ & $\mathrm{B}$ & B- & $\mathrm{C}+$ & $\mathrm{C}$ & $\mathrm{C}-$ & $\mathrm{D}+$ & $\mathrm{D}$ & D- & \\
\hline $\begin{array}{l}\text { Accomplishments: Individual contributions to the } \\
\text { project and impact on design and/or deliverables. } \\
\text { Understanding of relevant discipline-specific issues } \\
\text { related to the project. Documentation of individual work } \\
\text { and incorporation into project documentation. }\end{array}$ & & & & & & & & & & & & & \\
\hline $\begin{array}{l}\text { Process: Documented understanding the processes } \\
\text { inherent in design and an ability to employ these } \\
\text { processes in the development of the project. }\end{array}$ & & & & & & & & & & & & & \\
\hline $\begin{array}{l}\text { Reflective/Critical Thinking: Demonstrates ability to } \\
\text { think critically about many of the disciplinary, social, } \\
\text { ethical, personal, and interpersonal aspects of the project, } \\
\text { project partner, and their relationships. }\end{array}$ & & & & & & & & & & & & & \\
\hline $\begin{array}{l}\text { Teamwork/Leadership: Initiative and participation in } \\
\text { class and group work. Works with and helps other team } \\
\text { members, within and/or outside of formal team roles, to } \\
\text { accomplish team goals. Lab and project meeting } \\
\text { attendance. If applicable, leadership and fulfillment of } \\
\text { responsibilities associated with team position. }\end{array}$ & & & & & & & & & & & & & \\
\hline
\end{tabular}


Communication: Written and oral communication, both formally and informally, to all audiences: people familiar with project, and those who are not; people with both similar and different backgrounds; to teammates and to external people; to those who will be asked to continue your project in the future.

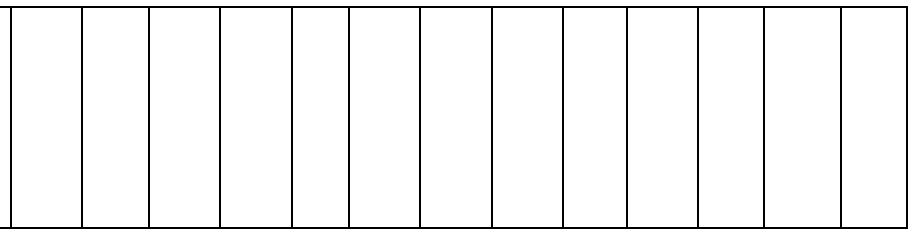

\section{Students:}

Overall grade you believe you have earned to this point in the semester:

Why? Please include specific examples of "Excellent", “Good", "Adequate”, or "Low Passing” (whichever corresponds to the grade you have given yourself) Accomplishments, Process, Reflective Thinking, Teamwork/Leadership and/or Communication in the box below. Please also include any additional information that was not reflected in the evidence you provided.

Advisors/TA: Grade earned to this point in the semester:

Explanation for grade (in box): 


\section{Appendix B: Grading Rubric for EPCS Junior and Senior}

\begin{tabular}{|c|c|}
\hline $\begin{array}{c}\text { Grades } \\
\text { A+ } \\
\text { A } \\
\text { A- }\end{array}$ & $\begin{array}{l}\text { A student who receives a grade of A in EPICS must exceed overall expectations and demonstrate } \\
\text { and document excellent achievement in each of the following areas: } \\
\text { Accomplishments: Responsibilities associated with project work are appropriate, but ambitious } \\
\text { for junior/senior course level, major, semester in EPICS, and number of credits. Individual } \\
\text { contributions to and/or ideas about the project are excellent and has a significant impact on design } \\
\text { and/or deliverables. Excellent understanding of relevant discipline-specific issues related to the } \\
\text { project. All work is documented, and significant contributions related to the project are } \\
\text { incorporated into the digitally archived design documentation. } \\
\text { Process: Demonstrates and documents an excellent understanding of the processes inherent in } \\
\text { design and an ability to employ these processes in the development of the project. } \\
\text { Reflective/Critical Thinking: Demonstrates and documents an ability to think critically about } \\
\text { many of the disciplinary, social, ethical, personal, and interpersonal aspects of the project, project } \\
\text { partner, and their relationships. } \\
\text { Teamwork/Leadership: If applicable, puts forth excellent effort to fulfill responsibilities } \\
\text { associated with team position. Demonstrates initiative and excellent participation in class and } \\
\text { group work. Shows a willingness to work with other team members, within and/or outside of } \\
\text { formal team roles, to accomplish team goals and leads when appropriate. Promotes team unity. } \\
\text { Excellent attendance. Assists others to learn new skills. } \\
\text { Communication: Communicates very effectively both written and orally, formally and informally, } \\
\text { to all audiences: people familiar with project, and those who are not; people with both similar and } \\
\text { different backgrounds; to teammates and to external people; to those who will be asked to } \\
\text { continue your project in the future. }\end{array}$ \\
\hline $\begin{array}{c}\text { Grades } \\
\text { B+ } \\
\text { B } \\
\text { B- }\end{array}$ & $\begin{array}{l}\text { A student who receives a grade of B in EPICS must meet overall expectations and demonstrate } \\
\text { and document good achievement in each of the following areas: } \\
\text { Accomplishments: Responsibilities associated with project work are appropriate for junior/senior } \\
\text { course level, major, semester in EPICS, and number of credits. Individual contributions to and/or } \\
\text { ideas about the project are good and has a positive impact on design and/or deliverables. Good } \\
\text { understanding of relevant discipline-specific issues related to the project. All work is documented, } \\
\text { and significant contributions related to the project are sufficiently incorporated into the digitally } \\
\text { archived design documentation. } \\
\text { Process: Demonstrates and documents a good understanding of the processes inherent in design } \\
\text { and an ability to employ these processes in the development of the project. } \\
\text { Reflective/Critical Thinking: Demonstrates and documents an ability to think critically about } \\
\text { some of the disciplinary, social, ethical, personal, and interpersonal aspects of the project, project } \\
\text { partner, and their relationships. } \\
\text { Teamwork/Leadership: If applicable, puts forth good effort to fulfill responsibilities associated } \\
\text { with team position. Demonstrates some initiative and good participation in class and group work. } \\
\text { Shows a willingness to work with other team members, within and/or outside of formal team roles, } \\
\text { to accomplish team goals. Good attendance. Acquires new knowledge when prompted by others. } \\
\text { Communication: Communicates effectively both written or orally, formally and informally, to } \\
\text { most audiences. }\end{array}$ \\
\hline
\end{tabular}




\begin{tabular}{|c|c|}
\hline $\begin{array}{c}\text { Grades } \\
\text { C+ } \\
\text { C } \\
\text { C- }\end{array}$ & $\begin{array}{l}\text { A student who receives a grade of C in EPICS must exceed minimum expectations and } \\
\text { demonstrate and document adequate achievement in each of the following areas: } \\
\text { Accomplishments: Responsibilities associated with project work are appropriate, but unambitious } \\
\text { for junior/senior course level, major, semester in EPICS, and number of credits. Individual } \\
\text { contributions to and/or ideas about the project are adequate and does not hinder the design and/or } \\
\text { development of deliverables. Some understanding of relevant discipline-specific issues related to } \\
\text { the project. Most work is documented, and significant contributions related to the project that are } \\
\text { incorporated into the digitally archived design documentation are minimal. } \\
\text { Process: Demonstrates and documents some understanding of the processes inherent in design } \\
\text { and little ability to employ these processes in the development of the project. } \\
\text { Reflective/Critical Thinking: Demonstrates and documents an ability to think critically about few } \\
\text { of the disciplinary, social, ethical, personal, and interpersonal aspects of the project, project } \\
\text { partner, and their relationships. } \\
\text { Teamwork/Leadership: If applicable, puts forth the minimal effort required to fulfill } \\
\text { responsibilities associated with team position. Participates in class and group work but does not } \\
\text { take initiative. Shows some willingness to work with other team members, within and/or outside of } \\
\text { formal team roles, to accomplish team goals. Good to fair attendance and level of participation in } \\
\text { class and group work. Acquires new knowledge when prompted by others. } \\
\text { Communication: Communicates adequately both written and orally, formally or informally, to } \\
\text { most audiences. }\end{array}$ \\
\hline $\begin{array}{c}\text { Grades } \\
\text { D+ } \\
\text { D } \\
\text { D- }\end{array}$ & $\begin{array}{l}\text { A student who receives a grade of D in EPICS just meets minimal expectations and demonstrates } \\
\text { and documents minimal achievement in each of the following areas: } \\
\text { Accomplishments: Responsibilities associated with project work are inadequate for junior/senior } \\
\text { course level, major, semester in EPICS, and number of credits. Very few individual contributions to } \\
\text { and/or ideas about the project and possibly hinders, through action or inaction, the design and/or } \\
\text { development of deliverables. Accomplishes little without significant assistance and often lacks } \\
\text { success. Little work is documented, and significant contributions related to the project are not } \\
\text { incorporated into the digitally archived design documentation. } \\
\text { Process: Demonstrates and documents little understanding of the processes inherent in design and } \\
\text { an inability to employ any process in the development of the project. } \\
\text { Reflective/Critical Thinking: Does not demonstrates or documents an ability to think critically } \\
\text { about the disciplinary, social, ethical, personal, and interpersonal aspects of the project, project } \\
\text { partner, and their relationships. } \\
\text { Teamwork/Leadership: If applicable, does not fulfill responsibilities associated with team } \\
\text { position. Participates in class and group work is minimal and does not take initiative. Shows little } \\
\text { willingness to work with other members to accomplish team goals. Poor attendance. } \\
\text { Communication: Communicates poorly both written and orally, formally or informally, to most } \\
\text { audiences. }\end{array}$ \\
\hline $\begin{array}{c}\text { Grac } \\
F\end{array}$ & $\begin{array}{l}\text { A student who receives a grade of F in EPICS fails to meet minimum expectations and does not } \\
\text { demonstrate or document minimal achievement in each of the following areas: } \\
\text { Accomplishments: Responsibilities associated with project work are inadequate for junior/senior } \\
\text { course level, major, semester in EPICS, and number of credits. Clearly hinders, through action or } \\
\text { inaction, the design and/or development of deliverables. Minimal or no accomplishments. } \\
\text { Documentation is incomplete. } \\
\text { Process: Demonstrates and documents no understanding of the processes inherent in design or an } \\
\text { inability to employ any process in the development of the project. } \\
\text { Reflective/Critical Thinking: Does not demonstrates or documents an ability to think critically } \\
\text { about the disciplinary, social, ethical, personal, and interpersonal aspects of the project, project } \\
\text { partner, and their relationships. } \\
\text { Teamwork/Leadership: If applicable, does not fulfill responsibilities associated with team } \\
\text { position. Participates in class and group work is minimal and does not take initiative. Shows little } \\
\text { willingness to work with other members to accomplish team goals. Very poor attendance. } \\
\text { Communication: Communicates poorly both written and orally, formally or informally, to most } \\
\text { audiences. }\end{array}$ \\
\hline
\end{tabular}




\section{Appendix C - Project Evaluation Rubric}

Team: Project(s):

Week:

Project Team Members:

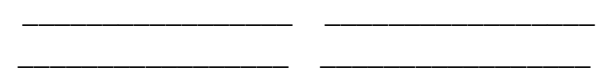

In the following box, list all of the significant project accomplishments since the beginning of the semester and where documentation of those can be found (add lines as necessary).

\begin{tabular}{|l|l|}
\hline $\begin{array}{l}\text { Project Progress and Accomplishments (e.g., completed user analysis, } \\
\text { DFMEA, or prototype) }\end{array}$ & $\begin{array}{l}\text { Where documentation can be found: (include } \\
\text { page \#s if in notebook and URLs if online) }\end{array}$ \\
\hline & \\
\hline & \\
\hline & \\
\hline
\end{tabular}

In the following box, list significant project activities planned for rest of semester

\begin{tabular}{|l|l|l|}
\hline Project Activity: & Responsible team member & Date To be completed by: \\
\hline & & \\
\hline & & \\
\hline & & \\
\hline
\end{tabular}

Directions: Project team members mark an "X" and Advisors/TAs mark an "O" in the appropriate box for each criterion.

\begin{tabular}{|c|c|c|c|c|c|c|c|c|c|c|c|c|c|}
\hline & \multicolumn{3}{|c|}{ Excellent } & \multicolumn{3}{|c|}{ Good } & \multicolumn{3}{|c|}{ Adequate } & \multicolumn{3}{|c|}{ Low passing } & \multirow[b]{2}{*}{$\mathrm{F}$} \\
\hline & A+ & A & A- & $\mathrm{B}+$ & $\mathrm{B}$ & B- & $\mathrm{C}+$ & $\mathrm{C}$ & $\mathrm{C}-$ & $\mathrm{D}+$ & $\mathrm{D}$ & D- & \\
\hline $\begin{array}{l}\text { Accomplishments and Overall Quality: Overall } \\
\text { quality. Project progress and accomplishments as stated } \\
\text { in semester goals and relative to overall timeline. } \\
\text { Feasibility of design or concept. Understanding of the } \\
\text { design issues, challenges, and constraints. Aesthetically } \\
\text { pleasing. }\end{array}$ & & & & & & & & & & & & & \\
\hline $\begin{array}{l}\text { Process: Detailed and appropriate plan for the semester. } \\
\text { Employs human-centered design process which includes } \\
\text { stakeholders throughout the process. Sufficient attention } \\
\text { to all stages of the design process. }\end{array}$ & & & & & & & & & & & & & \\
\hline $\begin{array}{l}\text { Reflective/Critical Thinking: Critical approach to the } \\
\text { design. Design exhibits / reflects consideration of the } \\
\text { social, ethical, and economic aspects of the project, as } \\
\text { well as aspects related to feasibility and sustainability. } \\
\text { Seeks and incorporates feedback. Decisions based on an } \\
\text { appropriate amount of information. }\end{array}$ & & & & & & & & & & & & & \\
\hline $\begin{array}{l}\text { Teamwork/Leadership: Team works together to } \\
\text { accomplish project and individual goals. Appropriate } \\
\text { division of tasks. Respect of fellow teammates. }\end{array}$ & & & & & & & & & & & & & \\
\hline
\end{tabular}


Dedication to meeting stated deadlines.

Communication: Written and oral communication, both formally and informally, to all audiences: people familiar with project, and those who are not; people with both similar and different backgrounds; to teammates and to external people; to those who will be asked to continue your project in the future.

Project Team Members:

Overall grade you believe your project has earned to this point in the semester:

Any additional information your project team would like to provide (in box):

\section{Advisors/TA:}

Project Grade earned to this point in the semester:

Explanation for grade (in box): 


\section{Appendix D: Community Partner Survey}

Dear Community Partner: We would greatly appreciate your feedback regarding your satisfaction regarding this recently delivered project. Please complete this form and return it to the EPICS Program Coordinator, Pam Brown, at the address below. Your specific responses will be kept confidential, but general information will be used to help us to better meet your needs and to educate the teams on how to better serve the community through their projects.

Community Organization:

Project:

Delivered on:

Primary community contact for this project:

Completed by (if different from above):

1. What were the project's objectives that you expected the team to accomplish?

2. Approximately what percentage of the design objectives do you think the design team achieved?

3. On a scale of $1-5$, how close was the final outcome to your initial expectations?

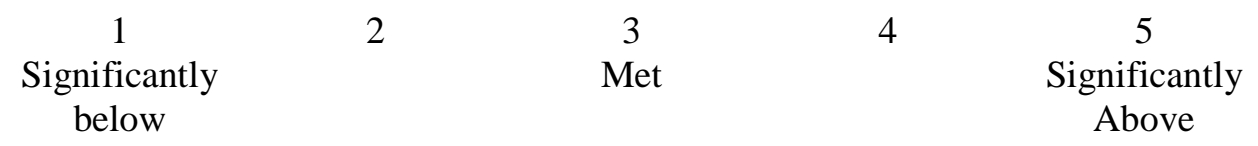

4. How beneficial do you anticipate this project to be for your organization?

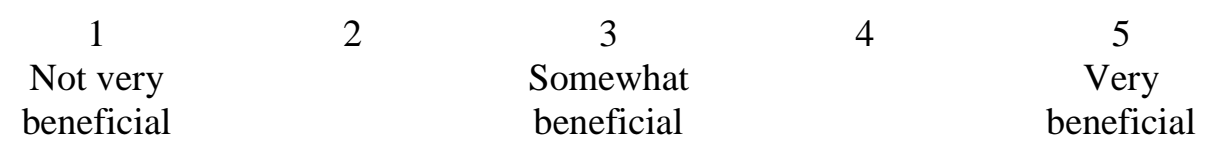

5. How would you rate the quality of communication between the design team and you or your organization during the project?

$\begin{array}{ccccc}1 & 2 & 3 & 4 & 5 \\ \text { Very poor } & \text { Poor } & \text { Adequate } & \text { Very good } & \text { Excellent }\end{array}$


6. Please rate your satisfaction with the project in the following areas:

\begin{tabular}{|c|c|c|c|c|c|}
\hline & $\begin{array}{c}\text { Very } \\
\text { dissatisfied } \\
1 \\
\end{array}$ & 2 & $\begin{array}{l}\text { Somewhat } \\
\text { satisfied } \\
3 \\
\end{array}$ & 4 & $\begin{array}{c}\text { Very } \\
\text { satisfied } \\
5 \\
\end{array}$ \\
\hline \multicolumn{6}{|l|}{ a. Quality of appearance of project } \\
\hline \multicolumn{6}{|l|}{$\begin{array}{l}\text { b.Quality of user manuals and } \\
\text { troubleshooting guides }\end{array}$} \\
\hline \multicolumn{6}{|l|}{$\begin{array}{l}\text { c. Timeliness of completion of } \\
\text { project }\end{array}$} \\
\hline \multicolumn{6}{|l|}{ d.Attention to safety } \\
\hline \multicolumn{6}{|l|}{ e.Attention to project user needs } \\
\hline \multicolumn{6}{|l|}{ f. Maintainability } \\
\hline \multicolumn{6}{|l|}{ g.Overall project } \\
\hline \multicolumn{6}{|l|}{$\begin{array}{l}\text { h.Quality of delivery of project } \\
\text { itself }\end{array}$} \\
\hline $\begin{array}{l}\text { i. Follow-up by students after } \\
\text { delivery }\end{array}$ & & & & & \\
\hline
\end{tabular}

7. How well have the maintenance and upkeep roles of EPICS and project partner identified?

1

Not addressed

by team

\section{2}

Adequately addressed by team
4 5 Very clearly identified by team

Any additional comments: 


\section{Appendix E - Alumni Questionnaire}

Education and Work Information

Q1. What year did you receive your bachelor degree?

Q2. Please select the College that you graduated from at Purdue with your bachelor degree:

a) Agriculture

b) Education

c) Engineering

i. Aeronautics and Astronautics

ii. Agricultural and Biological

iii. Biomedical

iv. Chemical

v. Civil

vi. Civil - Division of Construction Engineering and Management

vii. Electrical and Computer

viii. Engineering Education - Multidisciplinary

ix. Engineering Education - Interdisciplinary

x. Engineering Education - Division of Environmental and Ecological Engineering

xi. Industrial

xii. Materials

xiii. Mechanical

xiv. Nuclear

d) Liberal Arts

e) Krannert School of Management

f) Pharmacy

g) Science

h) Technology

i) Veterinary Medicine

Q3. Please indicate your highest level of education completed.
a) Bachelors
b) Bachelors. Currently pursuing a graduate degree
c) Masters
d) Masters. Currently pursuing another graduate degree
e) $\mathrm{Ph} . \mathrm{D}$.
f) Other

Q4. As best as you can recall, how many semesters did you participate in EPICS?
a) One
b) Two
c) Three
d) Four
e) More than four

Q5. Other than your classes and EPICS, what experiences did you have as an undergraduate student at Purdue? (Check all that apply.)
a) Internship
c) Co-op
d) Study Abroad
e) Global Design Team
f) Senior design capstone course (not EPICS)
g) GEARE

b) Design Competitions (for example: Solar Car contest, SAE, Concrete Canoe, Rube Goldberg, etc.) 
h) Service organization

i) Engineers Without Borders (EWB)

j) Fraternity/Sorority

k) Engineers for World Health

1) Engineers for a Sustainable World (ESW)

m) Other significant experience:

Q6. Have you had any professional work experience before pursuing a graduate degree? (not including the responsibilities of a full-time student and/or graduate teaching or research assistant)

a) Yes

b) No

Q7. Upon graduation, I sought employment from: (check all that apply).

a) Large corporations

b) Small/medium-sized companies

c) Start-up firms

d) Self-employed

e) Educational institutions (not including graduate school admission or graduate assistantships)

f) Government agencies

g) Community-based organizations

h) Other

Q8. Not including graduate assistantships, my first professional position was in a:

a) Large corporation

b) Small/medium-sized company

c) Start-up firm

d) Self-employed

e) Educational institution

f) Government agency

g) Community-based organization

h) Other

Q9. Do you currently work in a professional position? (not including the responsibilities of a full-time student and/or graduate teaching or research assistant)

a) Yes

b) No

Thinking about your first professional position, please answer the following:

Q10. When I started my first position, the percentage of time I spent on design was $(0-100 \%)$ :

\section{Items Regarding EPICS}

Thinking about your first professional position, to what extent did EPICS prepare you for the following?
a) Not at All
b) Small Extent
c) Some Extent
d) Large Extent
e) Very Large Extent
f) Not Applicable

Q11. applying design techniques:

Q12. being prepared for my work experience:

Q13. In comparison to your peers, how prepared were you for your first work experience?
a) Much Less

b) Less 

c) The Same
d) More
e) Much More

Q14. Is your current professional position different than your first professional position?
a) Yes
b) No

Q15. My current professional position is in a: (select one)

a) Large corporation

b) Small/medium-sized company

c) Start-up firm

d) Self-employed

e) Educational institution

f) Government agency

g) Community-based organization

h) Other

Thinking about your current professional position, please answer the following:

Q16. In my current position, the percentage of time I spend on design is $(0-100 \%)$ :

Q17. I have most recently been on a team with people from different disciplines within the past
a) month
b) three months
c) year
d) over a year
e) never

To what extent have your experiences in EPICS contribute to the following?
a) Not at All
b) Small Extent
c) Some Extent
d) Large Extent
e) Very Large Extent
f) Not Applicable

Q18. the confidence that I have in my work

Q19. an ability to design a system or process from start-to-finish

Q20. an ability to advance within my career

Q21. an appreciation for work related contributions of people from my own discipline

Q22. an appreciation for work related contributions of people from disciplines that are very different than my own

Q23. In comparison to your peers, how quickly have you advanced in your career?
a) Much Less Quickly
b) Less Quickly
c) The Same
d) More Quickly
e) Much More Quickly

Q24. Thinking about your undergraduate experiences, rank them in order of how well you learned to practice design by participating in the experiences. ("1" meaning "I learned to practice design best from this experience.")
a) EPICS
b) Coursework
c) Internship 


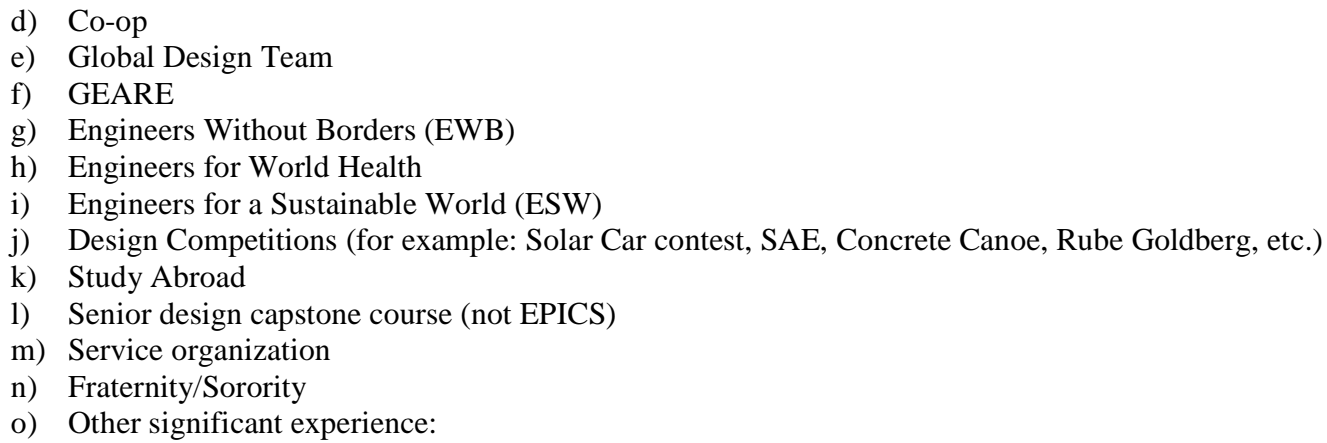

To what extent have your experiences in EPICS contribute to the following?
a) No Extent
b) Small Extent
c) Some Extent
d) Large Extent
e) Very Large Extent
f) Not Applicable

Q25. an ability to have effective relationships with my customers / clients / partners in my work

Q26. an ability to apply knowledge from my discipline to my work

Q27. an ability to acquire new knowledge in my work

Q28. an ability to work with people from my discipline

Q29. an ability to work with people from very different disciplines

Q30. an ability to effectively communicate my ideas to my co-workers

Q31. an ability to effectively communicate my ideas to customers / clients / partners

Q32. an ability to function in a team environment

Q33. an ability to demonstrate leadership in a team environment

Q34. an ability to demonstrate leadership in my profession

Q35. Thinking about your undergraduate experiences, rank them in order of how well they prepared you to enter the workplace as a professional. ("1" meaning "I received the best preparation from this experience.")

a) EPICS

b) Coursework

c) Internship

d) Co-op

e) Global Design Team

f) GEARE

g) Engineers Without Borders (EWB)

h) Engineers for World Health

i) Engineers for a Sustainable World (ESW)

j) Design Competitions (for example: Solar Car contest, SAE, Concrete Canoe, Rube Goldberg, etc.)

k) Study Abroad

l) Senior design capstone course (not EPICS)

m) Service organization

n) Fraternity/Sorority

o) Other significant experience:

Q36. In general, did your experience with EPICS influence your career choice? (If "yes", you will be asked how EPICS influenced your career choice.)

a) Yes

b) No 
Q37. I voted in the most recent type(s) of election(s): (select all that apply)
a) Presidential
b) Presidential primary
c) State
d) Local/municipal
e) None

Q38. Aside from voting, have you participated OR attempted to participate in government at the local, state, or national level?

a) Yes

b) No

Q39. I have most recently been a mentor within the last:
a) Month
b) Three months
c) Year
d) Over a year
e) Never

To what extent did your experiences in EPICS contribute to the following?
a) Not at All
b) Small Extent
c) Some Extent
d) Large Extent
e) Very Large Extent
f) Not Applicable

Q40. $\quad$ my desire to mentor

Q41. my appreciation for engineering as a profession that benefits society

Q42. an appreciation for the important role of the customer / client / partner in my design work

Q43. an ability to recognize the active role engineering can play in society

Q44. an ability to recognize ethical issues in my work

Q45. an ability to resolve ethical issues in my work

To what extent did your experiences in EPICS contribute to the following?
a) Not at All
b) Small Extent
c) Some Extent
d) Large Extent
e) Very Large Extent
f) Not Applicable

Q46. my desire to play an active role in my local community

Q47. my desire to play an active role in the global community

Q48. my desire to volunteer in activities related to my own discipline

Q49. my desire to volunteer in activities (not related to my discipline)

Q50. Thinking about your undergraduate experiences, rank them in order of how well they prepared you to function be a leader in your profession. ("1" meaning "I received the best preparation from this experience.")
a) EPICS
b) Coursework
c) Internship
d) Co-op
e) Global Design Team
f) GEARE 
g) Engineers Without Borders (EWB)

h) Engineers for World Health

i) Engineers for a Sustainable World (ESW)

j) Design Competitions (for example: Solar Car contest, SAE, Concrete Canoe, Rube Goldberg, etc.)

k) Study Abroad

1) Senior design capstone course (not EPICS)

m) Service organization

n) Fraternity/Sorority

o) Other significant experience:

Q51. Are you typically involved in a volunteer activity or activities that use your disciplinary skills? (i.e. skills related to your college major). If "yes", you will be asked to provide an example.

a) Yes

b) No

Q52. Are you typically involved in other types of volunteer activities? (that do not necessarily use your disciplinary skills). If "yes", you will be asked to provide an example.

a) Yes

b) No

Q53. Would you say that you actively seek to use engineering knowledge and skills to solve problems faced by society? If "yes", you will be asked to provide an example.

a) Yes

b) No

Q54. How did your experience with EPICS influence your career choice?

Q55. How have you participated in government at the local, state, or national level?

a) Served in a Voluntary Appointed Office (Commissioned or Committee)

b) Worked on a Campaign

c) Ran for Elected Office

d) Served in an Elected Office

e) Other:

Q56. What is an example of a volunteer activity that you participate in, using your disciplinary skills (i.e. skills related to your college major)?

Q57. How often do you volunteer for this particular activity?
a) Weekly
b) Monthly
c) Every Three Months
d) Annually
e) Less than once a year

Q58. What is an example of a general volunteer activity that you participate in? (This activity does not necessarily use your disciplinary skills.)

Q59. How often do you volunteer for this particular activity?

a) Weekly

b) Monthly

c) Every Three Months

d) Annually

e) Less than once a year

Q60. What is an example of a problem faced by society that you wish to solve using engineering knowledge and skills? 
Q61. What ways has EPICS influenced you personally and/or professionally? (Please use this space to provide any thoughts on this point that you have not already provided in the survey.)

\section{Demographic Information}

Q62. What is your gender?
a) Male
b) Female
c) I prefer not to respond

Q63. What is your ethnicity of origin? Please check any that you identify with.
a) White/Caucasian
b) African American
c) Hispanic
d) Asian
e) Native American
f) Pacific Islander
g) Other
h) I prefer not to respond

Interview Request

Q64. If you would like to be eligible to win an iPad 2, please provide your email address here:

Q65. Do you consent to the possibility of being contacted for an interview at some time in the future. (NOTE: This does not obligate you to interview, only that you consent to being contacted to arrange an interview.)

a) Yes

b) No

Q66. Please enter your email address to be contacted for an interview:

Q67. Please enter the 5-digit zip code of your home address: 